\title{
Adsorption of DNA onto gold nanoparticles and graphene oxide: surface science and applications
}

\author{
Juewen Liu* \\ Department of Chemistry, Waterloo Institute for Nanotechnology, University of Waterloo, Waterloo, \\ Ontario, Canada, N2L 3G1
}

Email: liujw@uwaterloo.ca

\begin{abstract}
The interaction between DNA and inorganic surfaces has attracted intense research interests, as a detailed understanding of adsorption and desorption is required for DNA microarray optimization, biosensor development, and nanoparticle functionalization. One of the most commonly studied surfaces is gold due to its unique optical and electric properties. Through various surface science tools, it was found that thiolated DNA can interact with gold not only via the thiol group but also through the DNA bases. Most of the previous work has been performed with planar gold surfaces. However, knowledge learned from planar gold may not be directly applicable to gold nanoparticles (AuNPs) for several reasons. First, DNA adsorption affinity is a function of AuNP size. Second, DNA may interact with AuNPs differently due to the high curvature. Finally, colloidal stability of AuNPs confines salt concentration, whereas there is no such limit for planar gold. In addition to gold, graphene oxide (GO) has emerged as a new material for interfacing with DNA. GO and AuNPs share many similar properties for DNA adsorption; both have negatively charged surfaces but can still strongly adsorb DNA, and both are excellent fluorescence quenchers. Similar analytical and biomedical applications have been demonstrated with these two surfaces. The nature of the attractive force however, is different for each of these. DNA adsorption on AuNPs occurs via specific chemical interactions but adsorption on GO occurs via aromatic stacking and hydrophobic interactions. Herein, we summarize the recent developments in studying non-thiolated DNA adsorption and desorption as a function of salt, $\mathrm{pH}$, temperature and DNA secondary structures. Potential future directions and applications are also discussed.
\end{abstract}


Biography. Juewen Liu received his BS from the University of Science and Technology of China in 2000 and $\mathrm{PhD}$ in Chemistry from the University of Illinois at Urbana-Champaign in 2005 with Professor Yi Lu. After postdoctoral research with Professor C. Jeffrey Brinker at the University of New Mexico and Sandia National Laboratories, he joined the Department of Chemistry of University of Waterloo as an Assistant Professor. He is also a member of the Waterloo Institute for Nanotechnology. $\mathrm{He}$ is interested in studying DNA-functionalized soft materials and nanomaterials for analytical and biomedical applications. He has received an Early Researcher Award from the Ontario Ministry of Research and Innovation.

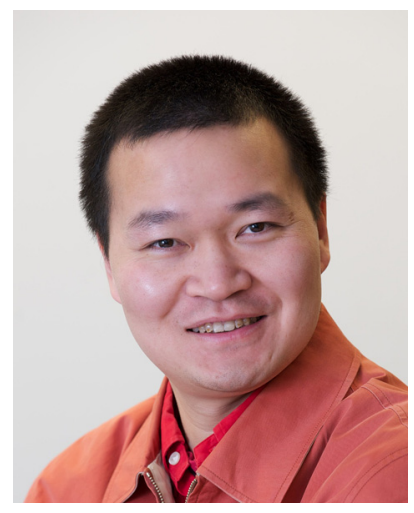

Juewen Liu 


\section{Introduction}

From a chemical standpoint, DNA is a block copolymer with four types of deoxyribonucleotide monomers differentiated by their bases. In the native double helical state, these bases are embedded, exposing only a negatively charged and chemically inert phosphate backbone. Such a structure allows for the maximal protection of genetic information, but for the same reason, DNA has long been considered to be a chemically boring molecule. With the invention of DNA chemical synthesis, singlestranded (ss) DNAs with arbitrary sequences become readily available, and are most often used as probes for complementary nucleic acids. ${ }^{1-3}$ In addition, certain ss-DNAs (i.e. aptamers) can selectively bind to various metal ions, small molecules and proteins. ${ }^{4-6}$ Compared to antibodies, aptamers are more stable and cost-effective to produce. Chemical synthesis allows for the incorporation of various modifications with less batch-to-batch variation. For these reasons, DNA has been a very popular molecule for biosensor development in the past two decades. ${ }^{7-13}$

Aside from molecular recognition, DNA/surface interaction has attracted more and more attention for the following two reasons. First, many technologies require DNA immobilization and one of the primary examples is DNA microarrays, where glass is often used as a substrate. ${ }^{1}$ In addition, sensor signaling and device incorporation also requires immobilization. Examples include surface plasmon resonance spectroscopy and mass-based detection, where a gold surface is often used. ${ }^{14}$ In these systems, the interaction between DNA and surface should be minimal so that the molecular recognition property of DNA is maintained. ${ }^{15}$ Planar gold surfaces are typically used for these applications and traditional surface science tools such as XPS, SERS, and neutron reflection can be applied to characterize DNA adsorption. ${ }^{15-33}$ The second reason for studying DNA adsorption stems mainly from applications related to various nanoparticles. ${ }^{34-40}$ Many DNA-functionalized nanoparticles have been tested for biosensor development, ${ }^{9,34,37,38,41,42}$ drug delivery ${ }^{43}$ and directed assembly. ${ }^{35,36}$ For example, both gold and carbon surfaces are excellent fluorescence quenchers, enabling fluorescence signaling upon DNA adsorption/desorption. ${ }^{44-47}$ At the same time, adsorbed DNA can protect gold nanoparticles (AuNPs) against salt-induced aggregation, ${ }^{48,49}$ control the growth AuNPs, ${ }^{50,51}$ modulate catalytic activities of AuNPs, ${ }^{52,53}$ and improve the specificity of DNA polymerases. ${ }^{54}$ Applications related to drug delivery can also be envisioned, ${ }^{50,55}$ since AuNP/DNA conjugates can be internalized by cells but free DNA cannot. ${ }^{55}$

While DNA adsorption onto planar gold has been extensively studied, less fundamental work has been done on DNA adsorption by AuNPs, ${ }^{48,56,57}$ despite the fact that numerous practical applications have 
already been reported. Compared to planar gold, dispersed AuNPs may allow for faster reaction rates. Due to larger surface curvature, AuNPs can accommodate a higher DNA density. ${ }^{58}$ AuNPs need to be studied in aqueous solution and are susceptible to salt-induced aggregation, while planar gold can be treated with high salt without stability concerns. At the same time, many surface science tools need to operate in ultrahigh vacuum and thus cannot be applied to studying nanoparticle dispersions. For these reasons, knowledge obtained from studying planar gold may not directly transfer to AuNPs.

We consider that a unique advantage of AuNPs is that they can maintain a "clean" surface for a long time, while it is very difficult to keep a planar gold surface clean. Gold has high surface energy and is likely to adsorb contaminants. There was a debate about the hydrophobicity of gold surface several decades ago $^{59,60}$ and in the 1980s, it was finally confirmed that gold is hydrophilic as long as the surface is clean, reflecting the difficulty to keep a gold surface clean. The standard cleaning procedure is to use "piranha solution" $\left(30 \% \mathrm{H}_{2} \mathrm{O}_{2}, 70 \% \mathrm{H}_{2} \mathrm{SO}_{4}\right)$ at high temperature. AuNPs on the other hand, are prepared and stored in aqueous solutions. Although the surface is likely to adsorb various compounds such as citrate to reduce surface energy, these adsorbed species can be easily displaced. Water may also serve as a protection agent to exclude contaminants.

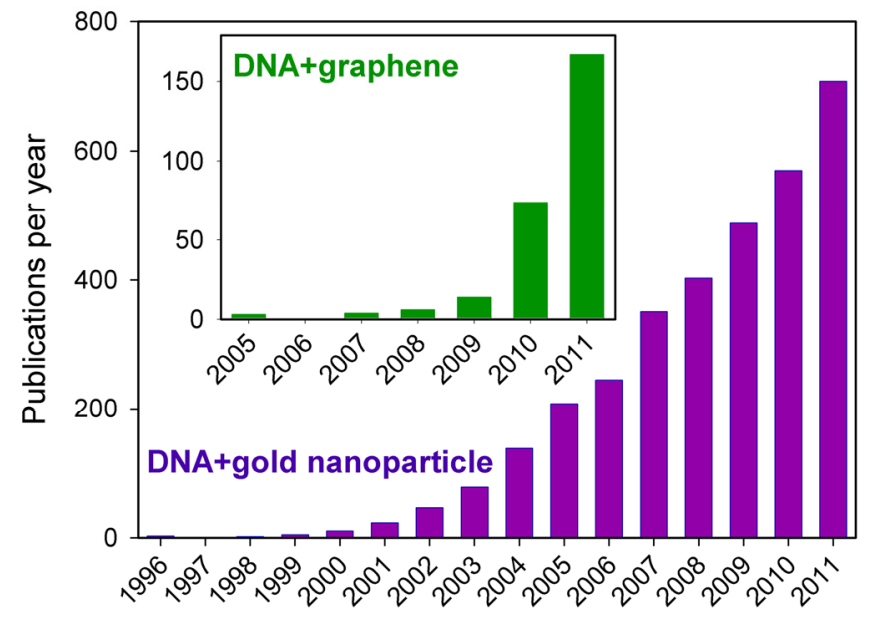

Figure 1. The number of papers published in each year on the topics of DNA and gold nanoparticles. Inset shows the number of papers related to DNA and graphene.

By searching the ISI Web of Knowledge database, we found an exponential growth in publications with the keywords DNA and gold nanoparticle, reaching over 700 papers in 2011 (Figure 1). In addition to AuNPs, interfacing DNA with graphene has also shown many promising applications and the number of publications exceeded 150 in 2011 (inset of Figure 1). Graphene oxide (GO) exhibits 
many similar properties as AuNP for DNA adsorption. For example, both are negatively charged colloids, good fluorescence quenchers and sensitive to DNA secondary structures for DNA adsorption. The interactions between DNA and AuNPs or GO are governed by a number of intermolecular forces, including electrostatic interaction, hydrophobic force, DNA base stacking, and chemical bonding. In this Perspective, we dissect the various reaction steps of non-thiolated DNA interacting with these two nanomaterials. Future work and potential applications based on the current understandings are also discussed.

2. Properties of DNA bases. To have a better understanding on DNA adsorption, we start with physicochemical properties of DNA bases so that various intermolecular forces can be interpreted. (1) Charge. A chemically synthesized $n$-mer DNA contains $n-1$ negative charges from the backbone phosphate whose $p K_{a}$ value is around 2. The $p K_{a}$ values of the bases are shown in Figure 2. Within the $\mathrm{pH}$ range from 5 to 8 , the bases are non-charged and therefore DNA is highly negatively charged at neutral $\mathrm{pH}$. Deprotonation occurs for $\mathrm{T}$ and $\mathrm{G}$ at $\mathrm{pH}$ greater than 9 while protonation occurs for $\mathrm{C}$ and $\mathrm{A}$ at $\mathrm{pH}$ below 4, rendering DNA a partially zwitterionic molecule. (2) Hydrophobicity. Hydrophobicity is often ranked by the $\log P$ value defined by the partition between octanol and water. A lower $\log P$ value indicates stronger hydrophilicity. As shown in Table 1, all the bases are quite hydrophilic, with cytosine being the most hydrophilic and adenine being the most hydrophobic. Compared to the sugar ring and the phosphate backbone, the bases are more hydrophobic. For example, D-ribose has a $\log P$ value of -2.32 , and the nucleosides all have lower $\log P$ values than the corresponding bases. Based on the $\log P$ values, individual bases might only produce a very weak hydrophobic force. On the other hand, strong hydrophobic interaction could still be achieved by multivalent interactions in a long DNA chain. (3) Size. The sizes of the nucleobases are important for calculating the maximal adsorption capacity (if adsorbed parallel to the surface). The bases all have quite similar sizes (Table 1), ${ }^{61}$ which is in good agreement with the diameter of a DNA duplex being $\sim 2 \mathrm{~nm}$. (4) Bonding. Chemical bonding with metals mainly comes from the bases. Base ring nitrogen and exocyclic keto groups are often used for binding to metal ions but the exocyclic amino groups are poor ligands since its lone-pair electron is delocalized. ${ }^{62,63}$ All the bases are aromatic and can achieve $\pi$-stacking with other bases and with $\pi$-electron containing surfaces such as graphene. 

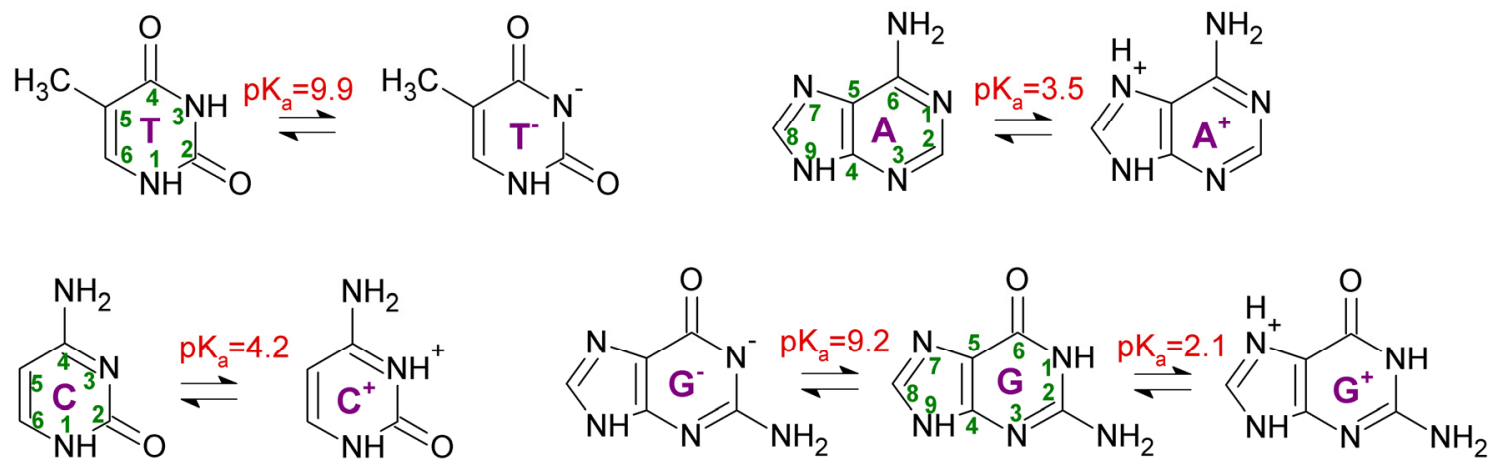

Figure 2. The structures of various DNA bases and their $p K_{a}$ values. The names of the bases are in purple and the numbering of each position is in green.

Table 1. $\log P$ values and surface areas of various DNA bases and nucleosides. $\log P$ data are taken from online database LOGKOW and base sizes are taken from reference ${ }^{61}$.

\begin{tabular}{lccll}
\hline DNA bases & Log P & Size $\left.\mathbf{( n m}^{\mathbf{2}}\right)$ & Nucleosides & Log P \\
Thymine & $-0.6 \pm 0.04$ & 1.42 & Thymidine & $-1.1 \pm 0.2$ \\
Cytosine & $-1.73 \pm 0.39$ & 1.27 & Cytidine & $-2.3 \pm 0.2$ \\
Adenine & $-0.14 \pm 0.03$ & 1.42 & Adenosine & $-1.1 \pm 0.1$ \\
Guanine & $-0.94 \pm 0.04$ & 1.54 & Guanosine & $-1.9 \pm 0.1$ \\
\hline
\end{tabular}

3. Surface property of AuNPs and GO. The most commonly used AuNPs for interfacing with DNA are synthesized by reducing $\mathrm{HAuCl}_{4}$ using sodium citrate. ${ }^{64}$ AuNPs ranging from $\sim 12 \mathrm{~nm}$ to over 60 $\mathrm{nm}$ can be obtained by simply changing the citrate concentration. Several equations for this reduction reaction have been proposed, ${ }^{65}$ and one of them is listed in Eq $1 .{ }^{66}$ Citrate is often added in excess. It is generally accepted that negatively charged citrate is weakly adsorbed by AuNPs to provide charge stabilization (Figure 3A). For $13 \mathrm{~nm}$ AuNPs, the $\mathrm{Na}^{+}$concentration is about $10 \mathrm{mM}$ from the added citrate, allowing AuNPs to stably disperse for many years. ${ }^{67}$ With a slight increase of salt concentration to $\sim 30 \mathrm{mM} \mathrm{Na}^{+}$, however, AuNPs start to aggregate due to charge screening and short-ranged attractive London force. Such aggregation is irreversible since heating cannot re-disperse aggregated AuNPs. It is also suggested that the surface of $\mathrm{AuNP}$ contains $\mathrm{AuCl}_{2}^{-}$species, which also contributes to the negatively charged surface.$^{68}$ AuNPs are popular for making colorimetric sensors for two reasons: (1) 
extremely high extinction coefficients allowing for visual observation at low $\mathrm{nM}$ and even pM particle concentration; (2) upon aggregation, AuNPs change color from red to blue. ${ }^{34,69}$

$2 \mathrm{HAuCl}_{4}+3 \mathrm{Na}_{3} \mathrm{C}_{6} \mathrm{H}_{5} \mathrm{O}_{6}$ (sodium citrate) $+1.5 \mathrm{H}_{2} \mathrm{O} \rightarrow 2 \mathrm{Au}_{0}+\mathrm{Na}_{2} \mathrm{C}_{5} \mathrm{H}_{6} \mathrm{O}_{5}$ (sodium ketoglutarate) + $3 \mathrm{CH}_{3} \mathrm{COONa}$ (sodium acetate) $+4 \mathrm{Na}^{+}+8 \mathrm{Cl}^{-}+2 \mathrm{H}^{+}+0.5 \mathrm{C}_{3} \mathrm{H}_{6} \mathrm{O}$ (acetone) $+5.5 \mathrm{CO}_{2}$

Graphene is a single layer of graphite. ${ }^{70-74}$ To disperse in water, GO is often prepared to contain various oxygenated groups (Figure 3B). ${ }^{75}$ The carboxyl groups are responsible for the negative charges on the GO surface. The surface of GO is highly heterogeneous with both hydrophobic prinstine graphene regions and hydrophilic oxidized regions. ${ }^{76-81}$ Therefore, DNAs adsorbed onto different regions are likely to have different adsorption affinity. GO can tolerate higher salt concentration than AuNPs and aggregated GO can at least partially re-disperse upon lowering the salt concentration. Interestingly, both AuNPs and graphene are excellent fluorescence quenchers. They completely quench a diverse range of adsorbed fluorophores and quantum dots (e.g. static quenching). ${ }^{44}$ They are also long-ranged dynamic quenchers whose quenching efficiency follows $d^{-4}$ dependency, where $d$ is the distance between fluorophore and quencher. ${ }^{82-87}$ In comparison, molecular quenchers usually follow a $d^{-6}$ dependency, and thus are more short-ranged.
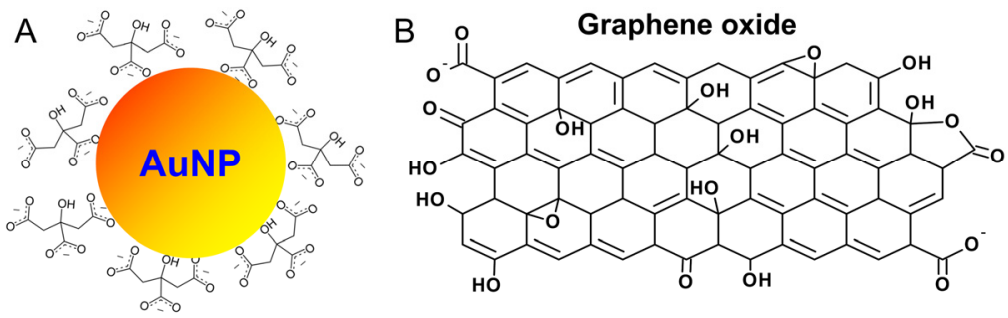

Figure 3. Schematics of surface chemistry of AuNPs (A) and GO (B).

4. Effect of salt concentration on DNA adsorption. Adsorption is the first step of any surface reaction. A long-ranged electrostatic repulsion prevents adsorption of negatively charged DNA onto negatively charged AuNPs or GO. To screen charge repulsion, salt is often added. Figure 4A shows salt-dependent DNA adsorption kinetics by AuNPs, where AuNPs are added to a FAM-labeled DNA such that adsorption is accompanied by fluorescence quenching. ${ }^{57}$ In the absence of additional salt (i.e. just $\sim 5 \mathrm{mM} \mathrm{Na}^{+}$from the AuNP solution and buffer), almost no DNA is adsorbed. The adsorption rate increases with higher salt concentrations. In the presence of greater than $60 \mathrm{mM} \mathrm{NaCl}$, adsorption is 
finished in 2 minutes as shown in Figure 4. However, AuNPs start to aggregate under such conditions. It needs to be pointed out that Figure 4A was collected using $1 \mathrm{nM}$ DNA and $1 \mathrm{nM}$ AuNP. If the DNA concentration is increased, adsorption rate might decrease as the surface coverage is increased (see discussions on adsorption capacity in Section 7). In 1997, Herne and Tarlov reported that almost no thiolated DNA was adsorbed onto planar gold if water was used (i.e. no salt). ${ }^{15}$ It is unclear about the electrostatic property of their gold surface, which might have been negative due to adsorbed molecules. Another possible explanation is that the authors used XPS for detecting adsorbed DNA, which may not be sensitive to surface coverage below 1\%. Due to the long Debye length in water, adsorbed trace amounts of DNA might form large electrostatic exclusion zones to repel incoming DNA. Without the colloidal stability problem, the authors investigated up to $1 \mathrm{M}$ salt and concluded that maximal adsorption was achieved using greater than $0.4 \mathrm{M} \mathrm{KH}_{2} \mathrm{PO}_{4}$. Overall, the trend of salt-dependent DNA adsorption is the same for planar and colloidal gold. The same trend has also been observed for DNA adsorption onto GO, where little adsorption occurred when dispersed in water but high salt resulted in fast DNA adsorption (Figure 4B). ${ }^{88,89}$ Therefore, a similar electrostatic barrier also exists between DNA and GO. GO appears to have higher stability against salt, or at least its aggregation is less easily visually detected, allowing millimolar $\mathrm{Mg}^{2+}$ to be used.
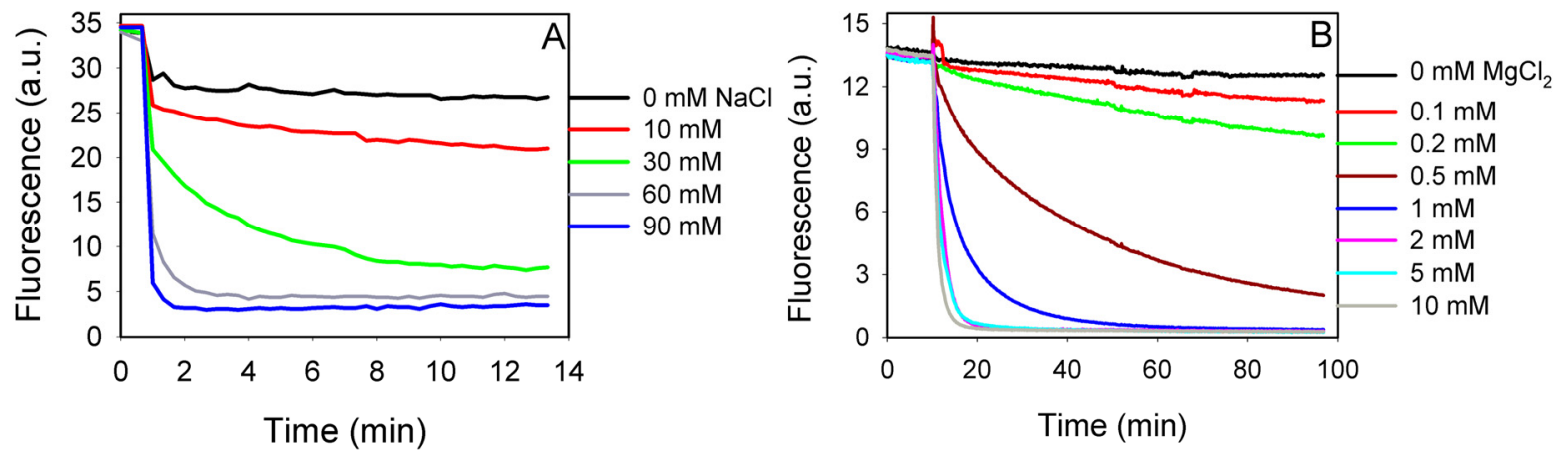

Figure 4. Kinetics of DNA adsorption by AuNPs (A) and by GO (B) as a function of salt concentration. Reprinted with permission from Ref 57 and 89. Copyright 2012 American Chemical Society.

5. Attractive forces. Since the electrostatic interaction is repulsive, attractive forces must exist to achieve stable adsorption. A number of spectroscopic studies have pointed out strong chemical bonding interactions between DNA bases and a gold surface. As surface enhanced Raman signal is strongly dependent on the distance to the metal surface, it was suggested that deoxyadenosine binds to AuNP surface via both the N6 exocyclic amino and the N7 atom, leading to highly stable binding (Figure 5). ${ }^{90}$ This strong adsorption has also been supported by the fact that poly-A DNA stably adsorbs on Au 
surface despite the presence of complementary poly-T DNA. ${ }^{19}$ Giese and McNaughton tested adenine adsorption onto various silver surfaces and found that both the N7 atom and amino group bond to a rough surface and Ag nanoparticles, however, only the N7 binds to silver island film, ${ }^{91}$ which has been supported by several other authors. ${ }^{92-94}$ Using scanning tunneling microscopy (STM), electron energy loss spectroscopy and ab initio calculations, Chen et al concluded that adenine adsorbs on $\mathrm{Cu}(110)$ via the amino group where the nitrogen shows $s p^{3}$ hybridization. ${ }^{95}$ Note that the lone-pair electron of the exocyclic amino group is normally $s p^{2}$ delocalized, where it is unlikely to contribute much to adsorption.

Camafeita et al studied the adsorption of guanine and its derivatives on AuNPs and concluded that adsorption occurred via the keto-N9H tautomer with the base perpendicular to the metal surface. ${ }^{96}$ Since the N9 position is used to link the sugar ring, it is unlikely to contribute to DNA adsorption. Based on SERS, Jang suggested deoxyguanosine binding via the $\mathrm{C}=\mathrm{O}$ together with the $\mathrm{N} 1$ nitrogen. In another study by Pergolese et al, several guanine containing compounds were found to tilt (neither flat nor perpendicular) with respect to the metal surface and adsorption was via the $\mathrm{C}=\mathrm{O}$ group and N7 atom (Figure 5). ${ }^{97}$ Jang suggested deoxycytidine binding via the N3 nitrogen as well as the keto oxygen (Figure 5). ${ }^{90}$ Doneux and Fojt studied cytidine adsorption onto Au(111) using in situ IR spectroscopy and concluded that chemisorption occurs via the N3 nitrogen exclusively. ${ }^{98}$ Thymine adsorption was the weakest and was proposed to be via the $\mathrm{C} 4$ keto oxygen. ${ }^{90}$

The orientation of the adsorbed bases is still under debate and mechanisms where the base ring is perpendicular, parallel or tilted with respect to the metal surface have been suggested. ${ }^{90,91,95}$ Several computational studies have also been carried out. ${ }^{99,100}$ In one report by Alavi et al, it was concluded that DNA bases are adsorbed parallel to gold surface and their organization is a function of base identity and density. ${ }^{101}$ While the exact interacting groups and DNA orientations remain to be fully studied, it is generally accepted that strong chemical bonding interactions exist between DNA bases and gold surfaces. In addition to chemical bonding, a number of other forces have been proposed to be responsible for DNA adsorption including van de Waals force, ${ }^{48}$ hydrophobic interactions, ${ }^{56}$ and induced dipole interaction (a type of van de Waals force). ${ }^{102}$ We consider that citrate capped AuNPs are highly hydrophilic and little DNA desorption was observed after washing with ethanol. ${ }^{57}$ As a result, hydrophobic force should not play a major role. 
DNA base adsorption by graphene has been extensively studied using computational studies. ${ }^{103-105}$ It is generally accepted that the base rings are parallel to the graphene surface to maximize $\pi$-stacking. Antony and Grimme concluded that the adsorption energy follows the order of $\mathrm{G}>\mathrm{A}>\mathrm{T}>\mathrm{C},{ }^{103}$ which is similar to $\mathrm{G}>\mathrm{A} \cong \mathrm{T} \cong \mathrm{C}$ obtained by Gowtham using density function calculations. ${ }^{105}$ By using atomic force microscopy to study the force required to peel DNA off the graphite surface, Manohar et al concluded that in a DNA strand, not all the bases are adsorbed and a diverse range of DNA conformations are likely to be present. ${ }^{106}$
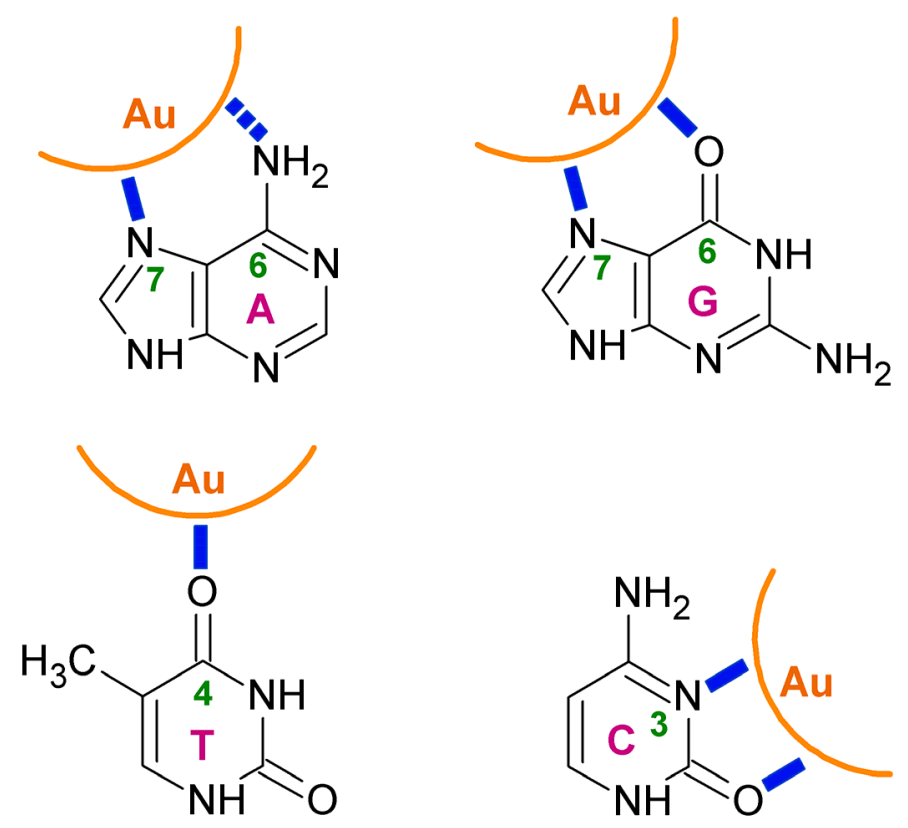

Figure 5. DNA bases (adenine, ${ }^{90,91}$ guanine, ${ }^{97}$ thymine, ${ }^{90}$ and cytosine ${ }^{90}$ ) adsorption onto gold surface based on the current literature. The numbers in the green are the positions of the atoms of the bases. Bonding interactions are indicated by the blue lines. The dashed blue line in A indicates a possible weak interaction.

6. DNA adsorption energy. While it is difficult to identify the contribution of each intermolecular force for DNA adsorption, DNA adsorption energy can be directly measured, thereby reflecting the magnitude of these forces. A number of surface science techniques have been used to measure the adsorption energy between DNA bases and a planar gold surface under ultrahigh vacuum conditions. Temperature programmed desorption (TPD) is a popular method, where a gold surface with adsorbed DNA bases is gradually heated and the desorbed bases are monitored. It was found that all the bases adsorb with a high energy (over $100 \mathrm{~kJ} / \mathrm{mol}$ ) indicating chemisorption with the order of $\mathrm{G}>\mathrm{A}>\mathrm{C}>\mathrm{T}$. ${ }^{107-}$ 
109 The detection methods for desorbed products include mass spectrometry and IR, all of which yielded similar results among several research groups. This energy is similar to alkylthiol binding to gold (e.g. 120-160 kJ/mol), leading to highly stable adsorption of even non-thiolated DNA. Adsorption energy measurements in vacuum might not be directly related to reactions in aqueous buffers. The DNA base adsorption energy in aqueous solution has been studied using isothermal titration calorimetry (ITC) but the reported adsorption energies are only a few $\mathrm{kJ} / \mathrm{mol},{ }^{110}$ decreasing by more than 40-fold compared to that measured under vacuum conditions. DNA bases might need to remove associated water molecules before chemisorption by AuNPs, which may contribute to the very low released heat of adsorption. In addition, incomplete binding might also occur since no data was presented on whether quantitative binding was achieved.

For DNA adsorption on graphene, the energy differs quite a bit for various bases. ITC measurements show the trend $\mathrm{G}>\mathrm{A}>\mathrm{C}>\mathrm{T}$. ${ }^{111}$ Interestingly, the heat of adsorption is a function of $\mathrm{GO}$ concentration and significantly more heat was released with more GO. For example, adenosine releases $2.26 \mathrm{~kJ} / \mathrm{mol}$ heat with $0.3 \mathrm{mg} / \mathrm{mL}$ of GO but $22.6 \mathrm{~kJ} / \mathrm{mol}$ heat with $1.0 \mathrm{mg} / \mathrm{mL}$ of GO. One possibility is that surface saturation and a higher GO concentration can adsorb more bases. Another explanation is that the surface is heterogeneous and certain regions can adsorb the bases with higher affinity. We have followed a 24-mer DNA adsorption using ITC. ${ }^{89}$ At the same time, DNA adsorption capacity was also measured. For the first few injections, close to quantitative adsorption can be achieved, but heat of adsorption also decreased, suggesting the effect of surface heterogeneity. The pristine graphene domains are likely to adsorb DNA more tightly with more heat released than highly oxidized domains. For each base, the adsorption energy appears to be lower for GO than that for gold, since adsorption by gold is achieved through chemical bonding, which is stronger than $\pi$-stacking.

7. Adsorption capacity. It is well-established that salt concentration determines the loading capacity of thiolated DNA by AuNPs, where higher salt results in more DNA adsorption. ${ }^{112-115}$ When the $\mathrm{NaCl}$ concentration is close to $1 \mathrm{M}, \sim 110$ thiolated DNA strands can be immobilized on each $13 \mathrm{~nm}$ AuNP. ${ }^{58,112,113}$ It is believed that salt can screen the charge repulsion among the neighboring DNAs and force DNA to adopt a stand-up conformation. Such a high DNA density is important for nuclease activity, ${ }^{115,116}$ cooperative DNA melting, ${ }^{117}$ increased binding affinity to $\mathrm{cDNA}^{118}$ and cell internalization. ${ }^{119}$ The adsorption capacity of non-thiolated DNA, however, is much less studied. Akerman and co-workers mixed non-thiolated DNA with $13 \mathrm{~nm}$ AuNPs and then measured DNA adsorption using gel electrophoresis. ${ }^{102}$ With AuNPs, the free DNA band is decreased compared to the 
reference sample without AuNPs. They measured the maximal loading of a 12-mer DNA to be $\sim 70$ per AuNP. We studied the adsorption capacity of non-thiolated DNA as a function of salt concentration and DNA length. ${ }^{57}$ After overnight incubation, the AuNPs were centrifuged and washed to remove free DNA in the supernatant, and adsorbed DNA was quantified after adding a high concentration of $\beta$ mercaptoethanol. As shown in Figure 6A, more DNA was adsorbed in the presence of more salt, consistent with the conclusion of thiolated DNA. The adsorption capacity is also a function of DNA length; short DNAs are adsorbed with a higher capacity. Our measured DNA loading is much lower than that obtained using gel electrophoresis. ${ }^{102}$ This may be attributed to the fact that we measured tightly adsorbed DNA after repeated washing while the gel method may also count weakly adsorbed DNA. In addition, the DNA concentration we used was also lower. Nevertheless, both studies confirmed that the number of adsorbed non-thiolated DNA is lower than thiolated DNA. Non-thiolated DNA might wrap around AuNP and thus occupy a larger footprint. ${ }^{120}$ It needs to be pointed out that non-thiolated DNA loading is often measured at relatively low salt to avoid AuNP aggregation; high loading might still be achieved if AuNPs could be stably dispersed under very high salt conditions. ${ }^{121}$

Based on the DNA loading capacity in Figure 6A, we propose that each adsorbed DNA forms an exclusion area and the excluded radius can be calculated by dividing the AuNP surface area by the number of adsorbed DNA. ${ }^{57}$ This exclusion radius is a sum of the DNA hydrodynamic radius on AuNP plus a length related to charge repulsion from the neighboring DNAs. This charge repulsion distance should be a function of Debye length and indeed a linear relationship was obtained by plotting these two (Figure 6B), suggesting an electrostatic influence of DNA loading capacity under experimental conditions. The longer DNA has a higher slope, which was attributed to its higher number of absolute charges.

We did not find any report on non-thiolated DNA loading capacity on planar gold, which may be significantly higher than the loading onto AuNPs since a much higher salt concentration can be used. We also measured the DNA adsorption capacity onto GO to be $200 \mathrm{nM} 24-\mathrm{mer}$ DNA for $20 \mu \mathrm{g} / \mathrm{mL}$ of GO. ${ }^{89}$ This translates to $\sim 440 \mathrm{~nm}^{2}$ for each DNA adsorbed if we consider that both sides of GO can adsorb DNA. This estimation may not be very accurate since it does not consider multi-layered GO that always present in such samples. The DNA loading capacity is much lower compared to that on AuNPs since the surface area of each $13 \mathrm{~nm}$ AuNP is $531 \mathrm{~nm}^{2}$. This lower capacity is also a reflection of the lower binding energy of DNA by GO. 

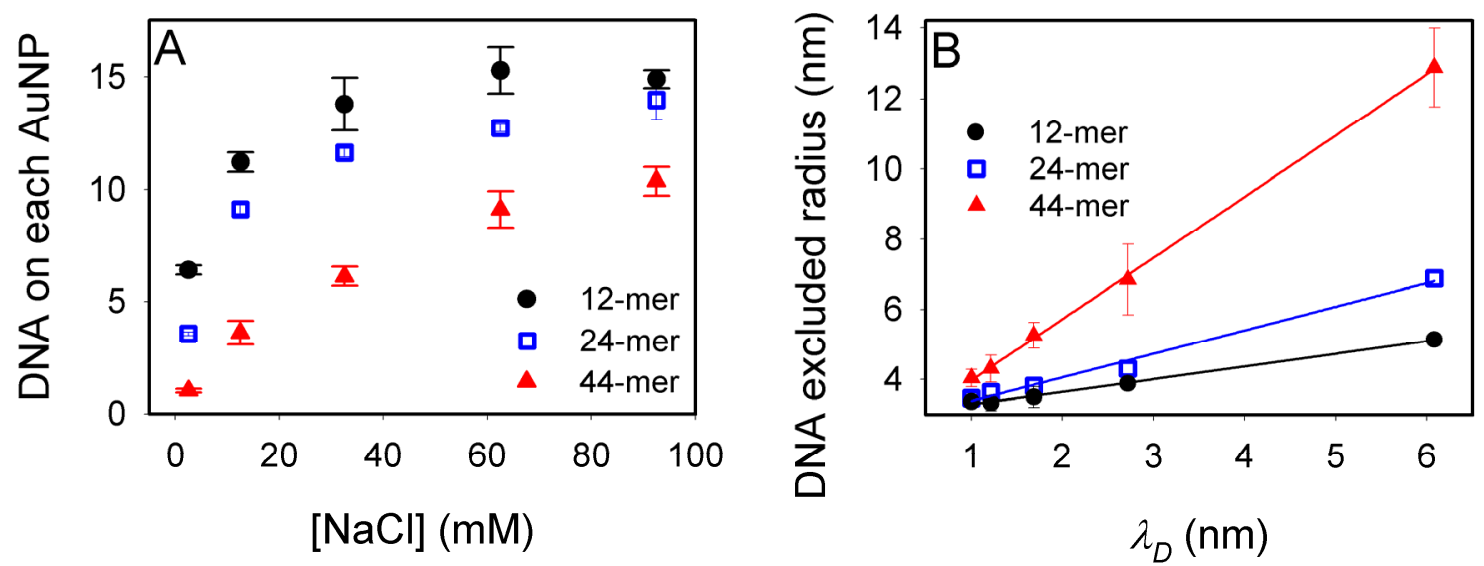

Figure 6. (A) DNA adsorption capacity on AuNPs as a function of $\mathrm{NaCl}$ concentration. Three DNA lengths were tested. (B) The linear relation between the DNA excluded radius and Debye length $\left(\lambda_{D}\right)$ under various $\mathrm{NaCl}$ concentrations. Reprinted with permission from Ref 57. Copyright 2012 American Chemical Society.

8. Effect of pH. Since most DNA adsorption experiments are performed at physiological conditions, the effect of $\mathrm{pH}$ has not attracted much attention. We found that $\mathrm{pH}$ plays an important role in DNA adsorption onto both AuNPs and GO. ${ }^{57,88,122}$ Using a DNA to AuNP ratio of 20:1, the adsorbed DNA increased from $\sim 20 \%$ to $95 \%$ by dropping $\mathrm{pH}$ from 7.6 to 3.5 (Figure $7 \mathrm{~A}$ ). ${ }^{57}$ This could be explained by both the protonation of citrate on AuNP as well as protonation of the DNA bases (e.g. C and A). The same is true for GO, where we observed quantitative DNA adsorption at $\mathrm{pH} 4$ and 5 but at $\mathrm{pH} 8$ only $\sim 30 \%$ DNA was adsorbed (Figure 7B). ${ }^{88}$ This GO experiment was performed at low salt to highlight the effect of $\mathrm{pH}$. The $\zeta$-potential of $\mathrm{GO}$ as a function of $\mathrm{pH}$ was recently reported; the absolute value of $\zeta$-potential decreased almost linearly with decreasing $\mathrm{pH}$ from 12 to 2, although the surface was negatively charged in the whole range. ${ }^{123}$ Therefore, GO is likely to contain a wide range of acid groups with different acidity. We performed ITC experiments and indeed significantly more heat was released at lower $\mathrm{pH} .{ }^{89}$ Based on this observation, we designed a biosensor regeneration method, where aptamer DNA probes were non-covalently adsorbed. At $\mathrm{pH} 7.5$, adsorbed aptamer probes are desorbed by adding target molecules to produce fluorescence signal. At $\mathrm{pH} 3.5$, desorbed aptamers re-adsorb and released target analytes are washed away to regenerate the sensors. ${ }^{124}$ 

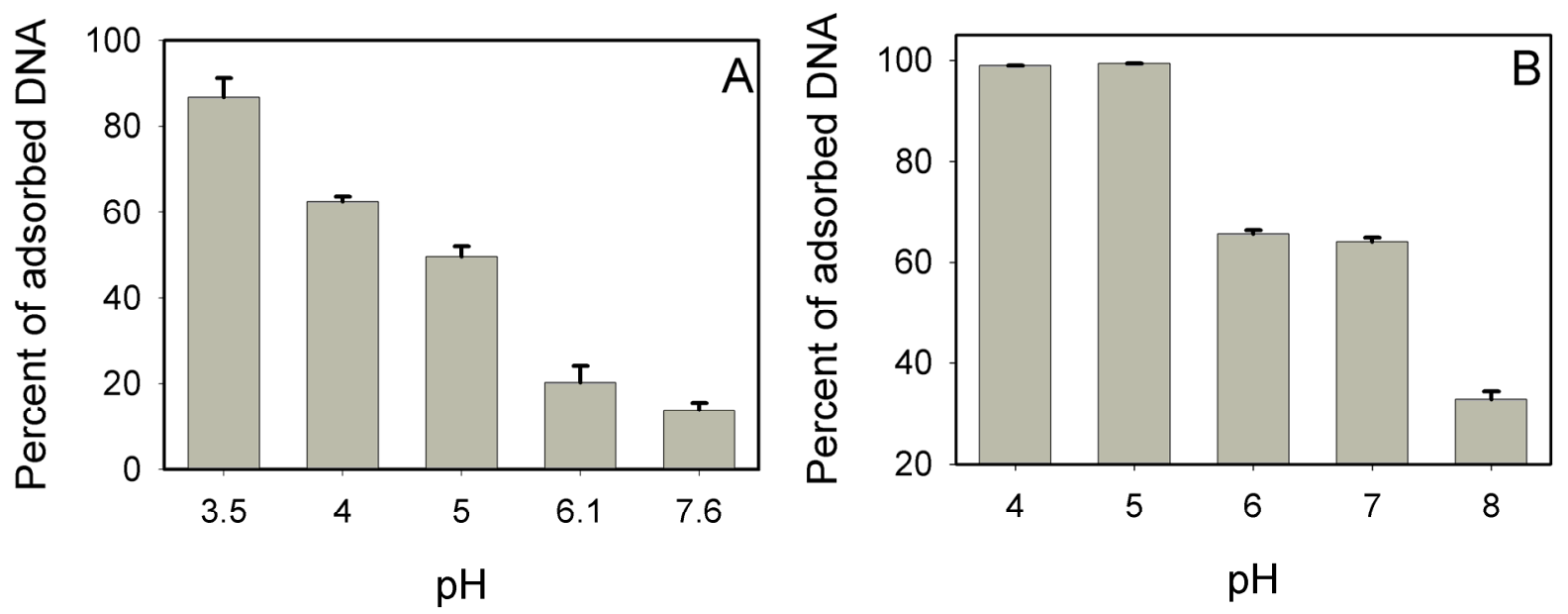

Figure 7. Effect of $\mathrm{pH}$ on the adsorption of FAM-labeled DNA onto AuNPs (A) and GO (B). Reprinted with permission from Ref 57 and 88. Copyright 2011 and 2012 American Chemical Society.

9. Effect of temperature. Temperature is an important parameter to study reaction mechanism. Li and Rothberg mixed a 50-mer DNA with AuNPs at various temperatures. Upon cooling and adding salt, AuNPs incubated with DNA at higher temperature were better protected, indicating more DNAs were adsorbed. ${ }^{48}$ Recently systematic temperature-dependent studies were carried out in various types of salts and the activation energy barrier for DNA adsorption was determined to vary from a few to $\sim 40$ $\mathrm{kJ} / \mathrm{mol}^{56}$ We studied DNA adsorption onto GO at various temperatures and also observed faster DNA adsorption at higher temperature. The activation energy in $0.1 \mathrm{mM} \mathrm{Mg}^{2+}$ was calculated to be 31.6 $\mathrm{kJ} / \mathrm{mol}$. These temperature-dependent studies confirmed the presence of an activation energy barrier. These activation energies are likely to decrease by raising ionic strength, which is supported by the adsorption kinetics data in Figure 4.

10. Adsorption isotherm and desorption. Adsorption isotherm measures the amount of adsorbed molecules as a function of DNA concentration at a fixed temperature, which provides insights into not only adsorption but also desorption. Akerman and co-workers reported non-thiolated DNA adsorption isotherm using gel electrophoresis. We measured the isotherm using centrifugation. In both cases, Langmuir isotherms were observed, indicating monolayer adsorption with adsorption/desorption equilibrium. Using a FAM-labeled 12-mer DNA, we found that the Langmuir constant was similar for high and low salt concentrations (Figure 8A). Since this constant reflects the relative rate of adsorption over desorption, and adsorption is much faster at higher salt, we postulate that desorption is also faster at higher salt concentrations. To test this, we monitored DNA desorption from AuNPs as a function of 
salt concentration (Figure 8C). Indeed, higher salt concentrations induced faster desorption. This is an intriguing result since salt is required for DNA adsorption. We propose that DNA displaces citrate on AuNP upon adsorption and thereafter the electrostatic repulsion between AuNP and adsorbed DNA is minimal. With low salt concentration, it might be more favourable for DNA to adapt an extended conformation on AuNP, exposing DNA bases to AuNP surface to strengthen adsorption. With high salt, the DNA internal charges are screened to produce more compact structures on the AuNP surface, reducing the number of contact points and facilitating desorption. The stability of alkylthiol molecules on $\mathrm{Au}$ surface is also known to decrease at high salt, ${ }^{125-127}$ and the same chemical mechanism might also contribute to the observed stability trend for non-thiolated DNA.
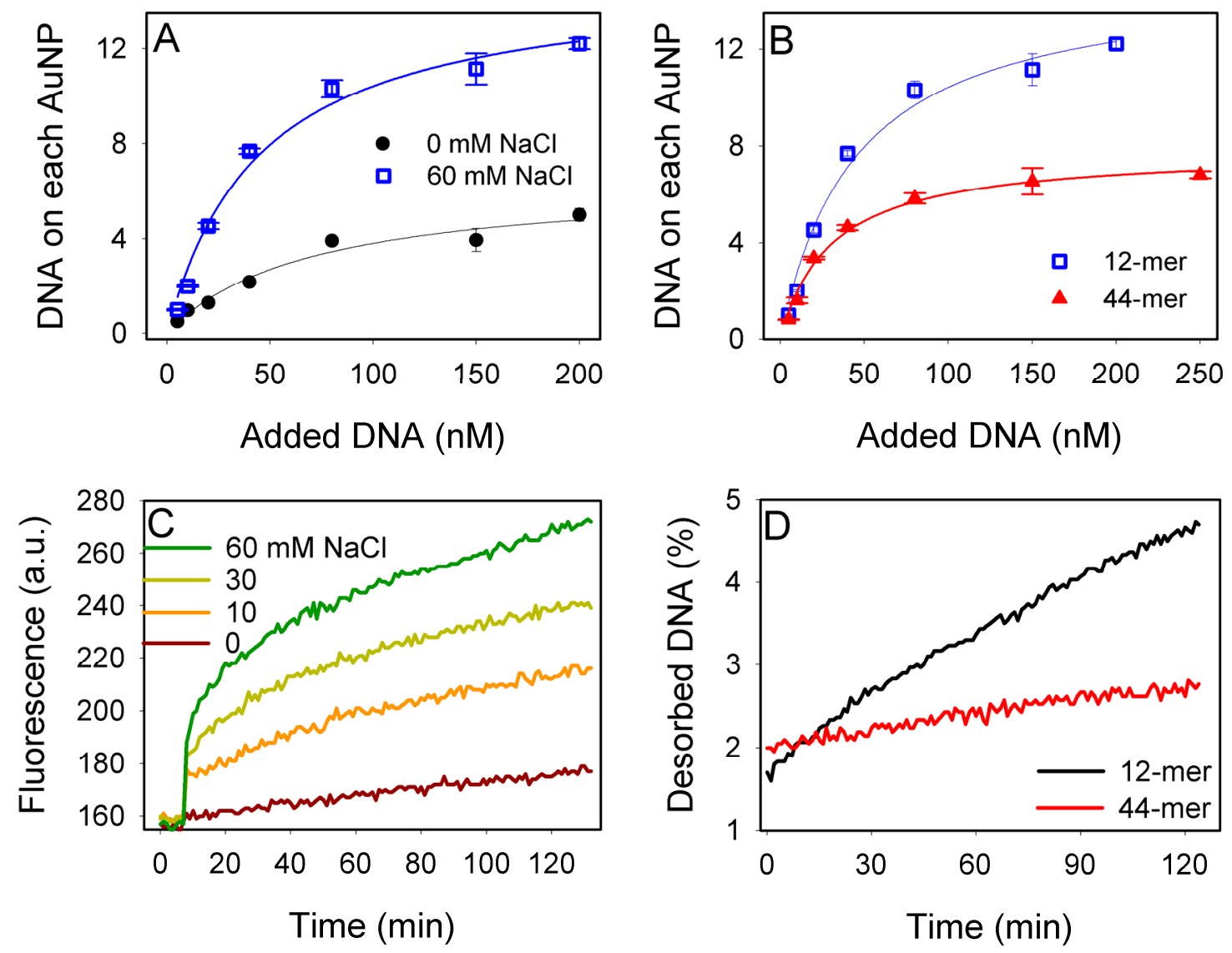

Figure 8. DNA adsorption isotherm as a function of salt (A) and DNA length (B). (C) DNA desorption kinetics in the presence of various $\mathrm{NaCl}$ concentrations for the 44-mer DNA, where $\mathrm{NaCl}$ was added at 5 min to induce desorption. (D) Desorption kinetics for the 12- and 44-mer DNA in $30 \mathrm{mM} \mathrm{NaCl}$. No AuNP aggregation was observed for the desorption experiment. Reprinted with permission from Ref 57. Copyright 2012 American Chemical Society. 
We also compared the adsorption isotherms of the 12 and 44-mer DNAs (Figure 8B), and observed that longer DNA has a higher Langmuir constant. Since longer DNA is adsorbed more slowly, it should also desorb more slowly, which has been supported by the desorption experiment (Figure 8D). Overall, DNA desorption from AuNP surface is very slow. For example, only $\sim 0.5 \%$ of a 44 -mer DNA desorbed in 2 hours.

We also measured the isotherm of DNA adsorption onto GO (unpublished data). Initially quantitative adsorption was achieved. After $\sim 40 \%$ of surface capacity, free DNA started to appear in the supernatant. It is unlikely that the Langmuir isotherm is the best description for this adsorption reaction since one of its basic assumptions is that all the surface sites need to have the same adsorption energy. Based on our ITC studies, a diverse range of adsorption affinities exist on GO. DNA desorption from GO has been extensively studied and more desorption occurred with lower salt concentration, which is opposite to that observed for AuNPs. This might be related to the fact that the negative charges on GO are permanent while the negative charges on AuNP come from adsorbed citrate and DNA. Even after overnight soaking in water, only $\sim 15 \%$ DNA desorbed from GO. Desorption can be further facilitated by using high $\mathrm{pH}$ and high temperature. After heating in $5 \mathrm{mM}$ Tris $\mathrm{pH} 9.5$, only $\sim 80 \%$ DNA desorption was achieved. The remaining $\sim 20 \%$ cannot be removed even after repeatedly washing under harsh conditions. ${ }^{89}$ This again is a reflection of surface heterogeneity. We reason that a small fraction of DNA is tightly adsorbed onto the pristine graphene region and reducing salt and raising $\mathrm{pH}$ is ineffective for removing these DNAs. Complete desorption can only be achieved by adding an excess amount of complementary DNA. ${ }^{89}$

11. Effect of nanoparticle size. The change of physical properties as a function of size is a hallmark of nanoscience. The most obvious size-dependent effect of AuNPs is probably its color change. DNA adsorption as a function of AuNP size has not been systematically investigated. By reading the literature, it appears that larger AuNPs possess a much stronger DNA adsorption affinity. Planar gold can be considered as an infinitely large AuNP and it adsorbs DNA very tightly. For example, even cDNA cannot hybridize with adsorbed DNA. ${ }^{15,19,22}$ Zhao and co-workers adsorbed a fluorescent thrombin aptamer onto 5 and $10 \mathrm{~nm}$ AuNPs and found more thrombin induced aptamer desorption occurred with the $5 \mathrm{~nm}$ AuNP sample. ${ }^{128}$ We also noticed that adding cDNA failed to induce DNA desorption from $13 \mathrm{~nm}$ AuNPs, but moderate desorption was observed from $5 \mathrm{~nm}$ AuNPs (unpublished data). When AuNP size is decreased to $\sim 2.5 \mathrm{~nm}$, not only cDNA but non-complementary DNA can 
produce effective desorption or displacement of adsorbed DNA. ${ }^{129}$ It appears that $5 \mathrm{~nm}$ is a critical size, above which AuNPs behaves like bulk gold with very strong adsorption affinity. Akerman and coworkers proposed that larger AuNPs are more easily polarized, where the induced dipole is responsible for DNA adsorption. ${ }^{102}$ We consider that if chemical bonding with DNA bases is responsible for DNA adsorption, increasing AuNP size may increase the number of free electrons to share with DNA bases. Interestingly, Kim and Surng reported adsorption of aptamer-functionalized quantum dots onto AuNPs up to $100 \mathrm{~nm}$, where analyte induced desorption was still observed. ${ }^{130}$ It is likely that quantum dots have played a role in affecting DNA/AuNP adsorption. The size effect of GO on DNA adsorption has not been reported. It appears that even nano-sized GO can still effectively adsorb DNA. ${ }^{131}$

12. Effect of DNA secondary structure. Since the DNA bases are responsible for DNA adsorption and the phosphate backbone poses the repulsive barrier, adsorption of ds-DNA and well-folded DNAs with shielded bases are kinetically disfavored. ${ }^{48,49,132}$ If the kinetic barrier can be overcome by adding salt, effective adsorption can still take place. For example, using a planar gold surface, Kimura-Suda et al showed that a duplex DNA made of $\mathrm{A}_{25}$ and $\mathrm{T}_{25}$ dissociated on the gold surface and $\mathrm{A}_{25}$ was adsorbed as ss-DNA. ${ }^{19}$ Therefore, the DNA hybridization energy is weaker compared to chemisorption of DNA by gold. Thermodynamically DNA adsorption by gold should still be favorable, regardless of DNA secondary structure. Akerman and co-workers observed ds-DNA adsorption onto AuNPs using gel electrophoresis. ${ }^{102,133}$ However, it was unclear whether the adsorbed DNA denatured on the gold surface or not in this case. Longer DNAs are more likely to form secondary structures and they diffuse more slowly, producing slower adsorption kinetics. ${ }^{48,88,132}$ Once adsorbed by AuNPs, however, longer DNAs desorb more slowly (Figure 8D), indicating more contact points with the gold surface and a stronger binding affinity.

Similar to AuNPs, ds-DNAs and folded DNAs are adsorbed more slowly by GO. ${ }^{45,132,134}$ Theoretical studies show that ds-DNA can be adsorbed either vertically, with the end base stacking with the graphene surface or horizontally, with the several end base pairs open to interact with the surface. ${ }^{135}$ Several reports on the adsorption of ds-DNA by graphene have been published and salt is generally required for adsorption to take place. ${ }^{136-138}$

13. Applications in biosensor development. Based on the DNA adsorption/desorption properties as well as the optical properties of AuNPs and GO, a diverse range of optical biosensors have been designed. ${ }^{7,37,139,140}$ AuNPs possess extremely high extinction coefficients such that low nM or even pM 
AuNPs can be vividly observed by the naked eye. Salt can induce AuNP aggregation to show blue or purple color (Figure 9A), while adsorbed DNA protects AuNPs against aggregation (Figure 9B). Adsorption of short ss-DNA is faster than long, ds- or folded DNA, which was originally demonstrated by Li and Rothberg for DNA detection and monitoring PCR products. ${ }^{48,49,141}$ If all the DNAs in the system are double-stranded, AuNPs aggregate upon adding salt (Figure 9C). Short ss-DNA can be generated via a DNAzyme cleavage reaction as shown in Figure 9D, allowing metal ions such as $\mathrm{Pb}^{2+}$ to be detected. ${ }^{142-145}$ DNA aptamer conformational change induced by target analytes has also been extensively tested with AuNPs and an example for $\mathrm{K}^{+}$detection is shown in Figure 9E. ${ }^{146-151}$ This method is popular because of its high sensitivity for visual detection and it allows for label-free detection. However, this method is also susceptible to false results. For example, the protection is quite moderate and high salt (e.g. $>300 \mathrm{mM} \mathrm{NaCl}$ ) can still induce aggregation even with adsorbed DNA. Protein adsorption (e.g. from serum samples), on the other hand, may prevent aggregation even with high salt.

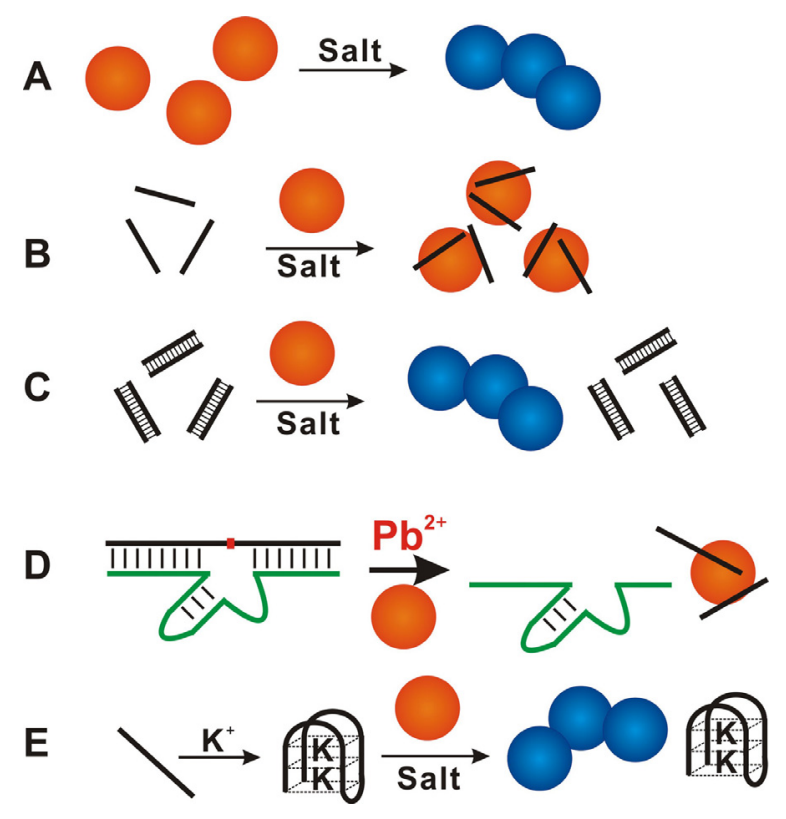

Figure 9. Colorimetric biosensors based on fast adsorption of short ss-DNA by AuNPs. (A) A low salt concentration can induce AuNP aggregation. (B) Adsorption of DNA can protect AuNPs from saltinduced aggregation. (C) Adsorption of ds-DNA is kinetically slow and AuNPs are not protected. (D) DNAzyme cleavage produces short ss-DNA for AuNP protection. (E) Aptamer folding impedes DNA adsorption and AuNPs are not protected. 
The same idea of assaying DNA conformation has also been applied using GO. Since the colloidal stability of GO is more difficult to quantify based on its optical appearance and DNA adsorption density is quite low, a fluorescently labeled DNA is often used so that DNA adsorption can be monitored by fluorescence quenching. ${ }^{132}$ From the sensing stand point, such a detection scheme produces "light off" sensors that have limited sensitivity. Alternatively, fluorescently labeled DNA is adsorbed onto GO first to result in quenched fluorescence. Upon adding target analytes, the adsorbed DNA desorb by changing DNA conformation and produce fluorescence. These methods have been used to detect DNA, ${ }^{45,152-156}$ metal ions, ${ }^{132,157}$ small molecules, ${ }^{131,158,159}$ proteins, ${ }^{160}$ and cells. ${ }^{161} \mathrm{We}$ consider that such physisorbed DNAs are prone to non-specific displacement and thus adding a covalent bond can further increase sensor specificity. ${ }^{89}$

As mentioned previously, since AuNPs either adsorb DNA too tightly (e.g. $>10-13 \mathrm{~nm}$ ) or too weakly (e.g. $<3 \mathrm{~nm}$ ), binding induced desorption has not been a popular signaling method, ${ }^{128}$ despite that AuNPs also possess excellent fluorescence quenching ability. For large AuNPs, even a single nucleotide adsorption might be strong enough, where DNA folding or hybridization may not induce desorption or fluorescence signal change. Whereas for GO, stable adsorption is achieved by multiple nucleotides. Therefore, target binding induced DNA conformational change can produce sufficient difference in adsorption affinity.

14. Effect on surface hybridization. One of the early motivations to study DNA adsorption on Au surfaces was to optimize DNA hybridization with surface immobilized thiolated DNA probes. ${ }^{15-33}$ To avoid non-specific adsorption of DNA bases, Herne and Tarlov found that short alkylthiol molecules such as mercaptohexanol $(\mathrm{MCH})$ can effectively displace non-specific DNA base adsorption and increase DNA hybridization efficiency. ${ }^{15}$ For AuNPs, the most popular method is to use a densely packed thiolated DNA, which serves as a blocking agent for itself. Hybridization can effectively take place since the density of DNA required to stabilize AuNPs is sufficient to block the AuNP surface. This has probably taken advantage of AuNP surface curvature such that the surface of AuNP is packed but the sequence outside can still have room to hybridize, especially when a spacer is used to separate the thiol group from the hybridization sequence. $\mathrm{Zu}$ and Gao report that the best hybridization efficiency is achieved when the thiolated DNA density is 40 on $13 \mathrm{~nm}$ AuNPs. If the density is too high, the hybridization efficiency decreases. ${ }^{114}$ The use of molecules like MCH to back fill the AuNP surface have also been tested, but its effect on DNA hybridization has not been systematically studied. ${ }^{162,163}$ 
15. A few technical notes. We presented in this Perspective that fluorescently labeled oligonucleotides are useful probes for DNA-based surface reactions. FAM-labeled DNA is the most commonly used probe since it has high quantum yield and is relatively more cost-effective to produce. At the same time, however, FAM is $\mathrm{pH}$ sensitive and essentially non-fluorescent when $\mathrm{pH}$ is lower than 5 , which needs to be taken into consideration when designing experiments. In addition, both AuNPs and GO have high extinction coefficients and fluorescence dropping due to just light extinction needs to be considered. For example, the as-prepared $13 \mathrm{~nm}$ AuNPs have an absorption value of $\sim 2.7$ at $520 \mathrm{~nm}$, where FAM emits. This means if 1000 photons are transmitted through a cuvette of $1 \mathrm{~cm}$ path-length, only 2 can get out. Although FAM molecules are dispersed in the cuvette and the average path-length is likely to be shorter, the extinction of light by this mechanism can still be very significant. Therefore, we often try to adjust AuNP extinction to be $\sim 0.3$ or lower to minimize extensive quenching.

16. Summary and future directions. Owing to the development of the self-assembled monolayer (SAM) technology, ${ }^{164}$ thiolated DNA has been the most popular choice to interface with gold surfaces. Since its initial report in 1996, thiolated DNA has offered an excellent control on DNA surface density and hybridization with good adsorption stability. It was soon realized that DNA bases can "nonspecifically" adsorb onto planar gold to prevent surface hybridization, leading to the invention of various surface blocking techniques to minimize non-specific interactions. ${ }^{15}$ This was less of a problem for AuNPs due to the high density of DNA required to achieve colloidal stability, where DNA served as its own blocking agent. Later it was found that non-thiolated DNA adsorption by AuNPs can also be very useful. ${ }^{48}$ With limited colloidal stability and also limited characterization tools, studying DNA adsorption by AuNPs appears to be quite difficult, leading to a number of controversies. In this Perspective, we have outlined several fundamental surface reaction steps for non-thiolated DNA adsorption onto AuNPs. We and many other groups have demonstrated that fluorescently labeled DNA is a useful probe, taking advantage of fluorescence quenching by AuNPs. Charge repulsion is the main barrier for DNA adsorption, which can be overcome by adding salt, reducing $\mathrm{pH}$, or increasing temperature as attractive forces take place at only very short DNA-to-gold distances. DNA adsorption by AuNPs is based on chemical interactions between DNA bases and AuNPs. The interactions are so strong that little desorption takes place. DNA adsorption also appears to be a function of AuNP size. The most commonly used $13 \mathrm{~nm}$ AuNPs are already large enough to show very strong adsorption, but AuNPs smaller than $5 \mathrm{~nm}$ appear to bind DNA weakly. DNAs with stable secondary structures are kinetically disfavored for adsorption by AuNPs but once adsorbed, the adsorption is still very strong. 
GO is a newly discovered material that shares many properties with AuNPs, such as surface charge and fluorescence quenching properties. The adsorption is weaker for GO since the main attractive force is non-covalent $\pi$-stacking. The GO surface is quite heterogeneous, displaying both hydrophobic regions favorable for DNA adsorption and highly oxidized regions that repel DNA. This leads to a diverse range of adsorption energies. It is likely that DNA adsorption by GO has a similar energy to aptamer binding and DNA hybridization, which can induce DNA desorption. For AuNPs, however, binding induced desorption hardly occurs. This difference has governed the different signaling methods used for developing DNA-based sensors involving AuNPs or GO.

We consider that many fundamental studies still need to be carried out to fuel practical applications and several examples are given here. 1) The details of the bonding interactions between DNA bases and gold surface need to be confirmed, including the orientation of the bases. It might be possible that each base can adopt several adsorption conformations. 2) AuNP size-dependent DNA adsorption needs to be carried out systematically. Both experimental work and computational simulation may be required to achieve full understanding. 3) So far, most work has been performed in water and studying the solvent effect may provide further insights. Adding organic solvents can probe fundamental intermolecular forces and also effect DNA hybridization and melting. ${ }^{165,166}$ 4) Work needs to be performed to understand adsorbed DNA inside macromolecular packed environments such as in cells. 5) Most of the current studies focus on DNA adsorption and desorption. Many other important steps such as surface reaction mechanisms and surface diffusion remain unclear. For example, the mechanism of cDNA induced DNA desorption from GO remains to be explored. In general, if cDNA is adsorbed first and then diffused to react, the reaction follows the Langmuir-Hinshelwood mechanism. On the other hand, if the cDNA directly react with adsorbed probe from the solution phase, it is an Eley-Rideal reaction.

With improved understandings on DNA surface interactions, related applications can also be envisioned. For example, currently the hybridization rate on AuNPs is still quite slow and understanding surface chemistry may accelerate this reaction. ${ }^{167}$ Biosensors based on DNA and surface interaction can be further improved to achieve higher sensitivity, better specificity and faster response. Using DNA to direct materials synthesis is another direction. A few reported cases have been published to prepare AuNPs using DNA. ${ }^{50,51}$ With better understanding of the fundamental adsorption effect, new materials may be prepared. ${ }^{168}$ Finally, AuNPs and GO can assist adsorbed DNA to be delivered into cells, and this has been rarely explored using non-thiolated DNA adsorbed by AuNPs. ${ }^{50}$ 
Acknowledgment. Funding for the work from the Liu lab described in this article is from the University of Waterloo, the Discovery Grant from the Natural Sciences and Engineering Research Council of Canada (NSERC), Early Researcher Award from the Ontario Ministry of Research and Innovation, Canadian Institutes of Health Research, and Canadian Foundation for Innovation.

\section{References:}

1 M. Schena, D. Shalon, R. W. Davis and P. O. Brown, Science, 1995, 270, 467.

$2 \quad$ S. Tyagi and F. R. Kramer, Nat. Biotechnol., 1996, 14, 303.

3 K. M. Wang, Z. W. Tang, C. Y. J. Yang, Y. M. Kim, X. H. Fang, W. Li, Y. R. Wu, C. D. Medley, Z. H. Cao, J. Li, P. Colon, H. Lin and W. H. Tan, Angew. Chem. Int. Ed., 2009, 48, 856.

4 D. S. Wilson and J. W. Szostak, Annu. Rev. Biochem., 1999, 68, 611.

$5 \quad$ S. D. Jayasena, Clin. Chem, 1999, 45, 1628.

6 M. Famulok, J. S. Hartig and G. Mayer, Chem. Rev., 2007, 107, 3715.

$7 \quad$ J. Liu, Z. Cao and Y. Lu, Chem. Rev., 2009, 109, 1948.

8 E. J. Cho, J.-W. Lee and A. D. Ellington, Annu. Rev. Anal. Chem., 2009, 2, 241.

9 D. Li, S. P. Song and C. H. Fan, Acc. Chem. Res., 2010, 43, 631.

10 M. Zhou and S. Dong, Acc. Chem. Res., 2011, 44, 1232.

11 A. A. Lubin and K. W. Plaxco, Acc. Chem. Res., 2010, 43, 496.

12 I. Willner and M. Zayats, Angew. Chem., Int. Ed., 2007, 46, 6408.

13 K. Sefah, J. A. Phillips, X. L. Xiong, L. Meng, D. Van Simaeys, H. Chen, J. Martin and W. H. Tan, Analyst, 2009, 134, 1765.

14 B. P. Nelson, T. E. Grimsrud, M. R. Liles, R. M. Goodman and R. M. Corn, Anal. Chem., 2001, 73, 1 .

15 T. M. Herne and M. J. Tarlov, J. Am. Chem. Soc., 1997, 119, 8916.

16 D. Y. Petrovykh, V. Perez-Dieste, A. Opdahl, H. Kimura-Suda, J. M. Sullivan, M. J. Tarlov, F. J. Himpsel and L. J. Whitman, J. Am. Chem. Soc., 2006, 128, 2.

17 D. Y. Petrovykh, H. Kimura-Suda, M. J. Tarlov and L. J. Whitman, Langmuir, 2004, 20, 429.

18 D. Y. Petrovykh, H. Kimura-Suda, L. J. Whitman and M. J. Tarlov, J. Am. Chem. Soc., 2003, $125,5219$.

19 H. Kimura-Suda, D. Y. Petrovykh, M. J. Tarlov and L. J. Whitman, J. Am. Chem. Soc., 2003, 125, 9014.

20 A. B. Steel, R. L. Levicky, T. M. Herne and M. J. Tarlov, Biophys. J., 2000, 79, 975.

21 A. B. Steel, T. M. Herne and M. J. Tarlov, Anal. Chem., 1998, 70, 4670.

22 R. Levicky, T. M. Herne, M. J. Tarlov and S. K. Satija, J. Am. Chem. Soc., 1998, 120, 9787.

23 L. K. Wolf, Y. Gao and R. M. Georgiadis, Langmuir, 2004, 20, 3357.

24 K. G. Olsen, D. J. Ross and M. J. Tarlov, Anal. Chem., 2002, 74, 1436.

25 K. A. Brown, S. Park and K. Hamad-Schifferli, J. Phys. Chem. C, 2008, 112, 7517.

26 W. J. Parak, T. Pellegrino, C. M. Micheel, D. Gerion, S. C. Williams and A. P. Alivisatos, Nano Lett., 2003, 3, 33.

27 P. Gong, C. Y. Lee, L. J. Gamble, D. G. Castner and D. W. Grainger, Anal. Chem., 2006, 78, 3326.

28 S. M. Schreiner, A. L. Hatch, D. F. Shudy, D. R. Howard, C. Howell, J. Zhao, P. Koelsch, M. Zharnikov, D. Y. Petrovykh and A. Opdahl, Anal. Chem., 2011, 83, 4288. 
C. Howell, J. Zhao, P. Koelsch and M. Zharnikov, Phys. Chem. Chem. Phys., 2011, 13, 15512. C.-Y. Lee, P.-C. T. Nguyen, D. W. Grainger, L. J. Gamble and D. G. Castner, Anal. Chem., 2007, 79, 4390.

31 C.-Y. Lee, P. Gong, G. M. Harbers, D. W. Grainger, D. G. Castner and L. J. Gamble, Anal. Chem., 2006, 78, 3316.

P. He, Y. Xu and Y. Fang, Anal. Lett., 2005, 38, 2597.

S. M. Schreiner, D. F. Shudy, A. L. Hatch, A. Opdahl, L. J. Whitman and D. Y. Petrovykh, Anal. Chem., 2010, 82, 2803.

N. L. Rosi and C. A. Mirkin, Chem. Rev., 2005, 105, 1547. Angew. Chem. Int. Ed., 2005, 44, 5100.

N. L. Rosi, D. A. Giljohann, C. S. Thaxton, A. K. R. Lytton-Jean, M. S. Han and C. A. Mirkin, Science, 2006, 312, 1027.

56 E. M. Nelson and L. J. Rothberg, Langmuir, 2011, 27, 1770.

X. Zhang, M. R. Servos and J. Liu, Langmuir, 2012, 28, 3896.

H. D. Hill, J. E. Millstone, M. J. Banholzer and C. A. Mirkin, ACS Nano, 2009, 3, 418.

J. R. Gardner and R. Woods, J. Electroanal. Chem. Interfacial Electrochem., 1977, 81, 285.

S. Tennyson, J. Colloid Interf. Sci., 1980, 75, 51.

K. M. Guckian, B. A. Schweitzer, R. X. F. Ren, C. J. Sheils, D. C. Tahmassebi and E. T. Kool, J. Am. Chem. Soc., 2000, 122, 2213.

R. M. Izatt, J. J. Christensen and J. H. Rytting, Chem. Rev., 1971, 71, 439.

V. A. Bloomfield, D. M. Crothers and I. Tinoco, Nucleic Acids: Structures, Properties, and Functions, University Science Books, Sausalito, 2000.

M. A. Hayat, Colloidal Gold: Principles, Methods, and Applications, Academic Press, San Diego, 1991. 
S. Kumar, K. S. Gandhi and R. Kumar, Ind Eng Chem Res, 2006, 46, 3128.

S. K. Balasubramanian, L. M. Yang, L. Y. L. Yung, C. N. Ong, W. Y. Ong and L. E. Yu, Biomaterials, 2010, 31, 9023.

67 J. Turkevich, Gold Bulletin, 1985, 18, 86.

A. Kumar, S. Mandal, R. Pasricha, A. B. Mandale and M. Sastry, Langmuir, 2003, 19, 6277.

R. Elghanian, J. J. Storhoff, R. C. Mucic, R. L. Letsinger and C. A. Mirkin, Science, 1997, 277, 1078.

70 K. S. Novoselov, A. K. Geim, S. V. Morozov, D. Jiang, Y. Zhang, S. V. Dubonos, I. V. Grigorieva and A. A. Firsov, Science, 2004, 306, 666.

A. K. Geim and K. S. Novoselov, Nat. Mater., 2007, 6, 183.

M. J. Allen, V. C. Tung and R. B. Kaner, Chem. Rev., 2009, 110, 132.

C. N. R. Rao, A. K. Sood, K. S. Subrahmanyam and A. Govindaraj, Angew. Chem. Int. Ed., 2009, 48, 7752.

A. K. Geim, Science, 2009, 324, 1530.

W. Gao, L. B. Alemany, L. Ci and P. M. Ajayan, Nat Chem, 2009, 1, 403.

T. Szabo, O. Berkesi, P. Forgo, K. Josepovits, Y. Sanakis, D. Petridis and I. Dekany, Chem. Mater., 2006, 18, 2740.

77 C. Gomez-Navarro, J. C. Meyer, R. S. Sundaram, A. Chuvilin, S. Kurasch, M. Burghard, K. Kern and U. Kaiser, Nano Lett., 2010, 10, 1144. W. Cai, R. D. Piner, F. J. Stadermann, S. Park, M. A. Shaibat, Y. Ishii, D. Yang, A. Velamakanni, S. J. An, M. Stoller, J. An, D. Chen and R. S. Ruoff, Science, 2008, 321, 1815. A. Lerf, H. He, M. Forster and J. Klinowski, J. Phys. Chem. B, 1998, 102, 4477. K. N. Kudin, B. Ozbas, H. C. Schniepp, R. K. Prud'homme, I. A. Aksay and R. Car, Nano Lett., $2007,8,36$.

81 K. A. Mkhoyan, A. W. Contryman, J. Silcox, D. A. Stewart, G. Eda, C. Mattevi, S. Miller and M. Chhowalla, Nano Lett., 2009, 9, 1058.

101 A. Maleki, S. Alavi and B. Najafi, J. Phys. Chem. C, 2011, 115, 22484. 
P. Sandstrom, M. Boncheva and B. Akerman, Langmuir, 2003, 19, 7537. J. Antony and S. Grimme, Phys. Chem. Chem. Phys., 2008, 10, 2722.

F. Ortmann, W. G. Schmidt and F. Bechstedt, Phys. Rev. Lett., 2005, 95, 186101.

S. Gowtham, R. H. Scheicher, R. Ahuja, R. Pandey and S. P. Karna, Phys. Rev. B, 2007, 76, 033401 .

S. Manohar, A. R. Mantz, K. E. Bancroft, C.-Y. Hui, A. Jagota and D. V. Vezenov, Nano Lett., $2008,8,4365$.

L. M. Demers, M. Oestblom, H. Zhang, N.-H. Jang, B. Liedberg and C. A. Mirkin, J. Am. Chem. Soc., 2002, 124, 11248.

M. Ostblom, B. Liedberg, L. M. Demers and C. A. Mirkin, J. Phys. Chem. B, 2005, 109, 15150. T. Boland and B. D. Ratner, Proc. Natl. Acad. Sci. U.S.A., 1995, $92,5297$.

A. Gourishankar, S. Shukla, K. N. Ganesh and M. Sastry, J. Am. Chem. Soc., 2004, 126, 13186. N. Varghese, U. Mogera, A. Govindaraj, A. Das, P. K. Maiti, A. K. Sood and C. N. R. Rao, ChemPhysChem, 2009, 10, 206.

L. M. Demers, C. A. Mirkin, R. C. Mucic, R. A. Reynolds, III, R. L. Letsinger, R. Elghanian and G. Viswanadham, Anal. Chem., 2000, 72, 5535.

S. J. Hurst, A. K. R. Lytton-Jean and C. A. Mirkin, Anal. Chem., 2006, 78, 8313.

Y. Zu and Z. Gao, Anal. Chem., 2009, 81, 8523.

W. J. Qin and L. Y. L. Yung, Biomacromolecules, 2006, 7, 3047.

D. S. Seferos, A. E. Prigodich, D. A. Giljohann, P. C. Patel and C. A. Mirkin, Nano Lett., 2009, 9, 308 .

R. Jin, G. Wu, Z. Li, C. A. Mirkin and G. C. Schatz, J. Am. Chem. Soc., 2003, 125, 1643.

A. K. R. Lytton-Jean and C. A. Mirkin, J. Am. Chem. Soc., 2005, 127, 12754.

D. A. Giljohann, D. S. Seferos, P. C. Patel, J. E. Millstone, N. L. Rosi and C. A. Mirkin, Nano Lett., 2007, 7, 3818.

T. Pellegrino, R. A. Sperling, A. P. Alivisatos and W. J. Parak, J. Biomed. Biotechnol., 2007, 2007, 26796.

X. Zhang, M. R. Servos and J. Liu, J. Am. Chem. Soc., 2012, DOI: 10.1021/ja303787e.

X. Zhang, M. R. Servos and J. Liu, J. Am. Chem. Soc., 2012, 134, 7266.

L. J. Cote, J. Kim, Z. Zhang, C. Sun and J. X. Huang, Soft Matter, 2010, 6, 6096.

P.-J. J. Huang, R. Kempaiah and J. Liu, J. Mater. Chem., 2011, 21, 8991.

N. Bhatt, P.-J. J. Huang, N. Dave and J. Liu, Langmuir, 2011, 27, 6132.

A. J. Viudez, R. Madueno, T. Pineda and M. Blazquez, J. Phys. Chem. B, 2006, 110, 17840.

C. S. Weisbecker, M. V. Merritt and G. M. Whitesides, Langmuir, 1996, 12, 3763.

W. J. Wang, C. L. Chen, M. X. Qian and X. S. Zhao, Anal. Biochem., 2008, 373, 213.

D. J. Maxwell, J. R. Taylor and S. Nie, J. Am. Chem. Soc., 2002, 124, 9606.

Y. S. Kim and J. Jurng, Analyst, 2011, 136, 3720.

Y. Wang, Z. H. Li, D. H. Hu, C. T. Lin, J. H. Li and Y. H. Lin, J. Am. Chem. Soc., 2010, 132, 9274.

S. J. He, B. Song, D. Li, C. F. Zhu, W. P. Qi, Y. Q. Wen, L. H. Wang, S. P. Song, H. P. Fang and C. H. Fan, Adv. Funct. Mater., 2010, 20, 453.

P. Sandstrom and B. Akerman, Langmuir, 2004, 20, 4182.

Z. W. Tang, H. Wu, J. R. Cort, G. W. Buchko, Y. Y. Zhang, Y. Y. Shao, I. A. Aksay, J. Liu and Y. H. Lin, Small, 2010, 6, 1205.

X. Zhao, J. Phys. Chem. C, 2011, 115, 6181.

H. Z. Lei, L. J. Mi, X. J. Zhou, J. J. Chen, J. Hu, S. W. Guo and Y. Zhang, Nanoscale, 2011, 3, 3888 .

M. Liu, H. Zhao, S. Chen, H. Yu and X. Quan, Chem. Comm., 2012. 
B. S. Husale, S. Sahoo, A. Radenovic, F. Traversi, P. Annibale and A. Kis, Langmuir, 2010, 26, 18078.

139 Y. J. Song, W. L. Wei and X. G. Qu, Adv. Mater., 2011, 23, 4215.

140 T. Kuila, S. Bose, P. Khanra, A. K. Mishra, N. H. Kim and J. H. Lee, Biosens. Bioelectron., 2011, 26, 4637.

141 H. Li and L. J. Rothberg, Anal. Chem., 2004, 76, 5414.

142 Z. Wang, J. H. Lee and Y. Lu, Adv. Mater., 2008, 3263.

143 H. Wei, B. Li, J. Li, S. Dong and E. Wang, Nanotechnology, 2008, 19, 095501.

144 J. H. Lee, Z. Wang, J. Liu and Y. Lu, J. Am. Chem. Soc., 2008, 130, 14217.

145 P. C. Ray, A. Fortner and G. K. Darbha, J. Phys. Chem. B, 2006, 110, 20745.

146 J. Wang, L. H. Wang, X. F. Liu, Z. Q. Liang, S. P. Song, W. X. Li, G. X. Li and C. H. Fan, Adv. Mater., 2007, 19, 3943.

147 L. Li, B. X. Li, Y. Y. Qi and Y. Jin, Anal. Bioanal. Chem., 2009, 393, 2051.

148 V. Guieu, C. Ravelet, S. Perrier, Z. Y. Zhu, S. Cayez and E. Peyrin, Anal. Chim. Acta, 2011, 706, 349.

149 X. W. Xu, J. Wang, K. Jiao and X. R. Yang, Biosens. Bioelectron., 2009, 24, 3153.

150 S. J. Chen, Y. F. Huang, C. C. Huang, K. H. Lee, Z. H. Lin and H. T. Chang, Biosens. Bioelectron., 2008, 23, 1749.

151 J. Zhang, L. H. Wang, D. Pan, S. P. Song, F. Y. C. Boey, H. Zhang and C. H. Fan, Small, 2008, 4, 1196.

152 H. F. Dong, W. C. Gao, F. Yan, H. X. Ji and H. X. Ju, Anal. Chem., 2010, 82, 5511.

153 F. Li, Y. Huang, Q. Yang, Z. T. Zhong, D. Li, L. H. Wang, S. P. Song and C. H. Fan, Nanoscale, 2010, 2, 1021.

154 M. Zhou, Y. M. Zhai and S. J. Dong, Anal. Chem., 2009, 81, 5603.

155 Y. Guo, L. Deng, J. Li, S. Guo, E. Wang and S. Dong, ACS Nano, 2011, 5, 1282.

156 W. Wu, H. Hu, F. Li, L. Wang, J. Gao, J. Lu and C. Fan, Chem. Comm., 2011, 47, 1201.

157 Y. Q. Wen, F. F. Xing, S. J. He, S. P. Song, L. H. Wang, Y. T. Long, D. Li and C. H. Fan, Chem. Comm., 2010, 46, 2596.

158 Y. J. Song, K. G. Qu, C. Zhao, J. S. Ren and X. G. Qu, Adv. Mater., 2010, 22, 2206.

159 C.-H. Lu, J. Li, M.-H. Lin, Y.-W. Wang, H.-H. Yang, X. Chen and G.-N. Chen, Angew. Chem., Int. Ed., 2010, 49, 8454.

160 H. X. Chang, L. H. Tang, Y. Wang, J. H. Jiang and J. H. Li, Anal. Chem., 2010, 82, 2341.

161 L. Wang, K.-Y. Pu, J. Li, X. Qi, H. Li, H. Zhang, C. Fan and B. Liu, Adv. Mater., 2011, 23, 4386.

162 S. Park, K. A. Brown and K. Hamad-Schifferli, Nano Lett., 2004, 4, 1925.

163 W. Zhao, W. Chiuman, M. A. Brook and Y. Li, Chembiochem, 2007, 8, 727.

164 J. C. Love, L. A. Estroff, J. K. Kriebel, R. G. Nuzzo and G. M. Whitesides, Chem. Rev., 2005, 105, 1103.

165 B. D. Smith and J. Liu, J. Am. Chem. Soc., 2010, 132, 6300.

166 A. Zaki, N. Dave and J. Liu, J. Am. Chem. Soc., 2012, 134, 35.

167 A. E. Prigodich, O.-S. Lee, W. L. Daniel, D. S. Seferos, G. C. Schatz and C. A. Mirkin, J. Am. Chem. Soc., 2010, 132, 10638.

168 T. A. C. Kennedy, J. L. MacLean and J. Liu, Chem. Comm., 2012, DOI: 10.1039/C2CC32841K. 